\title{
Design Fixation: A comparison between Native and Foreign Domains
}

\author{
V. Mahesh ${ }^{1}$, P.V. Raja Shekar ${ }^{2}$, P. Pramod Kumar ${ }^{3}$, M. Kantha Reddy and Vishvaksena. Ravichandran \\ ${ }^{1}$ Dept. of Mechanical Engineering, ${ }^{2}$ Dept. of Physics, ${ }^{3}$ Dept. of Computer Science and Engineering, \\ ${ }^{1,2,3}$ SR Engineering College, Warangal, Telangana, India \\ ${ }^{4}$ IUCEE, Hyderabad, Telangana, India \\ ${ }^{5}$ University of California Berkeley, USA \\ 1'v.mahesh2@gmail.com, ${ }^{2}$ pvrsleo@gmail.com, ${ }^{3}$ pramod_kumar_p@srecwarangal.ac.in \\ ${ }^{4}$ kanthareddy_m@yahoo.com, ${ }^{5}$ vishsena@gmail.com
}

\begin{abstract}
Design fixation negatively impacts design outcomes and is generally referred as the designer's inability to consider multiple strategies to formulate and solve a design need. The present paper will assess some of the design skills of Indian engineering students viz. fluency, flexibility and originality. To evaluate these skills, a more general task of designing a disposable spill-proof coffee cup is given to the sample. The sample consisted of students from native domain (Mechanical and Civil engineering departments) and foreign domain (other than the mentioned departments). The results were discussed with reference to the level of fixation of students of native and foreign domains, while providing two different kinds of environments, one with a specified sample example and other with a design pattern.
\end{abstract}

Keywords - Design Fixation; Design Skills; Fixation Group; Control Group

\footnotetext{
V. Mahesh

Dept. of Mechanical Engineering,

SR Engineering College, Warangal, Telangana, India

v.mahesh2@gmail.com
}

\section{Introduction}

Design fixation is one of the major concerns in engineering idea generation, which hinders the generation of novel ideas. Designing is considered to be one of the most challenging and important human activity; it is complex, requires high intelligence and skills [1]. The effect of pictorial examples [2-4], example solutions and physical models [5-7] on imparting fixation in engineering idea generation process have been studied by many researchers. However, the use of previous designs can adversely impact the design process in the form of design fixation [3], a potentially limiting adherence to existing designs. The information native domain designers absorb and register in their mind has the potential to fixate them during the design process and result in lack of innovation where as the foreign domain designers don't have that kind of reference knowledge regarding the design domain, so the chances of innovation is relatively high. Dahl and Moreau [8] demonstrated that subjects exposed to within-domain examples employed fewer far/out-ofdomain analogies in generating solutions and that the originality of the solutions produced increased relatively when subjects were encouraged to use analogies extensively and given no example solutions. Marsh et al. [9] found that within-domain examples caused subjects to be biased towards generating solutions with similar features to those found in the examples. A common and often commented upon form of fixation is premature commitment to a particular problem solution. 
Consequently, the designers stop pursuing the search for alternative solutions. This premature commitment thus results in fewer solutions. These findings establish that any experiment with exposure to a within-domain example prior to ideation, can cause fixation.

Hence, in the present paper, it is felt interesting to evaluate whether the domain knowledge will show an influence on the design skills in engineering students. The methodology of the work carried out to assess the design fixation is discussed in the following sections. The authors focused on investigating the differences in creativity and level of design fixation of students belonging to native domain (Mechanical and Civil engineering departments) and foreign domain (other than the mentioned departments). The results of the work carried out by the authors can throw light on the design fixation in engineering students.

\section{Methodology}

\section{A. Sample and Size}

The sample is a set of students belonging to all the years (and of all disciplines) of undergraduate engineering programme. The following specifications have been considered while choosing the sample:

पthe sample size is atleast 30 in each institute,

पthe sample consisted of both boys and girls of approximately same numbers and

Dthe participants were not having prior knowledge of the design task conducted.

The sample is taken from SR Engineering College Warangal, VR College of Engineering Warangal and B V Raju Institute of Technology, Hyderabad and the following design task is conducted.

\section{B. Description of the Design problem}

As the primary goal of this paper is to evaluate the effects of fixation on designers of native and foreign domain, a more general and simple task of designing a disposable spill-proof coffee cup (that can be easy to use by any user) is chosen. The participants were divided into two groups of equal numbers viz. control and fixation groups, wherein each group has students of native and foreign domain, thereby they fall into four categories viz. control-native domain (C-ND), control-foreign domain (C-FD), fixation-native domain (F-ND) and fixation-foreign domain (F-FD). The control group is provided with the design problem and is not provided with any example solution or alternative representation of the design problem, whereas, the fixation group is provided with the design problem and also a sample solution with some description. The solution provided is a Styrofoam cup with a plastic seal top with a tube connected with a mouthpiece to allow the coffee outlet as shown in Figure 1.

Participants were provided with a drawing chart, pen, pencil and eraser to sketch their designs. They work on the design task individually and not in teams. Participants had 45 minutes to generate as many ideas as possible. On completion of the task, participants are given 30 minutes to answer a questionnaire to help analyze their perceptions.
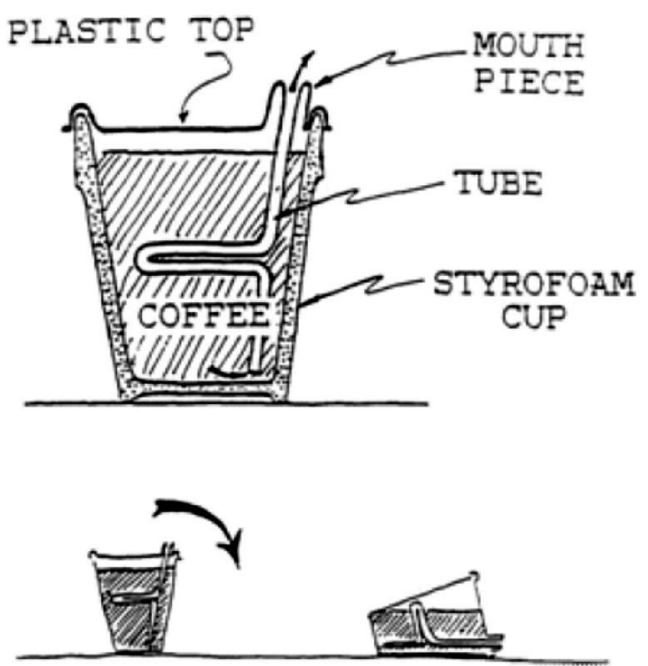

Fig 1. Example solution provided to fixation group

\section{Measures of Design Fixation}

Design fixation is an undesired phenomenon, which has a negative impact on the design skills. It inhibits designers thought process and cripples him ability to explore and expand the design space. Hence for assessing the design fixation, the three sub-skills of divergent thinking viz. fluency, flexibility and originality were considered as listed in Table 1. In addition to these, three design parameters viz. meeting the intent, simplicity and user-friendly are assessed from the drawings given by the participants to the design task. 
Table 1. Divergent Thinking Sub-skills and Metrics

\begin{tabular}{|c|l|l|l|}
\hline S.No & Sub-skill & \multicolumn{1}{|c|}{ Definition } & Metric \\
\hline 1 & Fluency & $\begin{array}{l}\text { Ability to generate } \\
\text { many solutions } \\
\text { consistently }\end{array}$ & $\begin{array}{l}\text { Quantity of ideas } \\
\text { generated }\end{array}$ \\
\hline 2 & Flexibility & $\begin{array}{l}\text { Ability to explore } \\
\text { design space in } \\
\text { many directions }\end{array}$ & $\begin{array}{l}\text { Variety of ideas } \\
\text { generated }\end{array}$ \\
\hline 3 & Originality & $\begin{array}{l}\text { Ability to "think } \\
\text { outside the box," } \\
\text { generate } \\
\text { unexpected } \\
\text { solutions }\end{array}$ & $\begin{array}{l}\text { Originality of } \\
\text { ideas generated }\end{array}$ \\
\hline
\end{tabular}

The fluency and flexibility were identified from their corresponding normalized scores. In case of measuring originality two different originality scores are computed (mean originality and maximum originality). Mean originality is the average scores of all the ideas, while maximum originality score corresponds to the best idea. It should be noted that it is the best idea one is interested in rather than the number of ideas. The formula used to determine the originality score ' $S$ ' for idea ' $i$ ' is

$$
\begin{gathered}
\mathrm{Si}=9\{\% \mathrm{H}-\% \mathrm{C}\}+1 \\
\% \mathrm{H}-\% \mathrm{~L}
\end{gathered}
$$

where $\% \mathrm{H}$ is highest frequency, $\% \mathrm{C}$ is frequency of idea and $\%$ L is lowest frequency.

\section{Hypothesis}

The following two hypotheses are considered and tested in the present study:

H1: Designers of Native Domain are more fixated than that of Foreign Domain.

$\mathrm{H} 2$ : Creative levels in control group are much higher than in fixation group in both native domain and foreign domain groups.

\section{Results And Discussion}

To ensure reliable data for analysis, the sample solutions that deviated from the prior instructions were not considered. This has increased the sanctity of the data. To ensure reliable and uniform scoring method, a set of instructions has been drafted for the evaluators. Two evaluators have graded the responses from the students independently. A crosscheck of grades is performed against each other to check for any bias or inconsistency. In case of any bias or inconsistency, the response sheet is forwarded for third evaluation.

The following observations can be inferred from the analysis of design solutions as well as from Figures 2 4:

a. Students of native domain start the design process with a mental model of the design solution, modify it to fit the task at hand, and add details in the design process.

b. F-ND students with a sample reference feel more at ease since they are likely to posses minimum design knowledge. Whereas C-ND students also have minimum design knowledge but they are not provided with any sample reference. Hence, the chances of generating novel ideas are more comparatively with native domain participants in fixation group.

c. Students of native domain are more concerned about the domain values than producing novel ideas when compared to foreign domains. It severely limits their creativity and results in pedestrian design solutions.

d. Both F-FD and C-FD students have no relevant design abilities with respect to the given design task. Hence, the F-FD students most probably follow the sample reference as their design base and construct some designs. Whereas C-FD students have neither domain specific knowledge nor a sample reference design base. Hence, they are considered as naïve and the chances of innovation may be at best when compared to remaining three other cases.

e. The C-ND students have given more number of design solutions whereas the fluency in F-FD students is very less.

f. The maximum and mean flexibilities among C-FD students are higher compared to the other three groups. They are found to be the least in case of F-ND students.

g. Majority of the students in native domain have shown a low originality score and high levels of fixation. The maximum and mean originalities of $\mathrm{C}$ FD students are proven to be higher than all the other three groups. 
h. The three design parameters viz. meeting the intent, simplicity and user-friendly are also found to be more in the C-FD students.

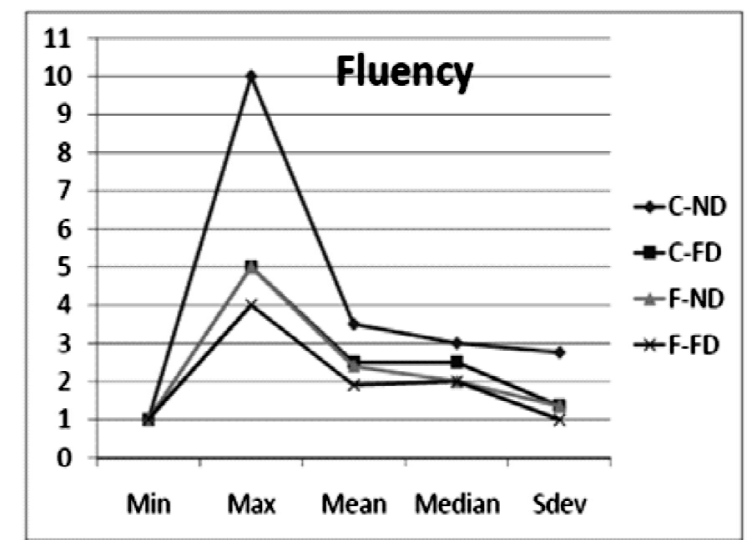

Fig 2. Comparision of fluency between native and foreign domains

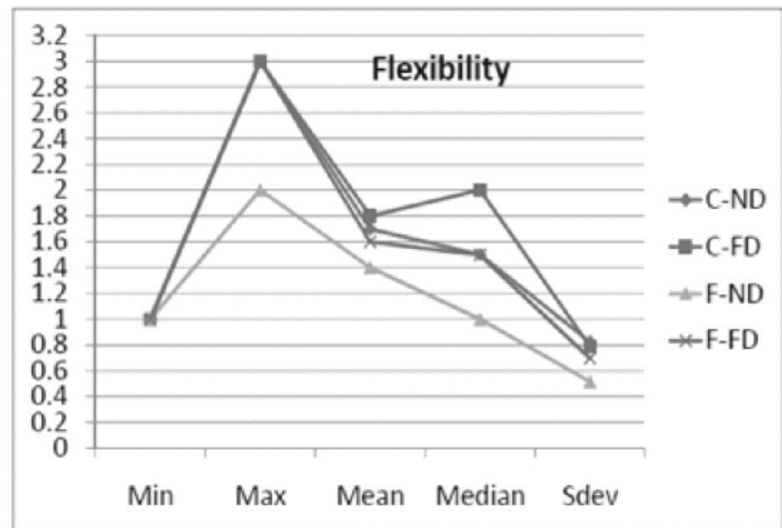

Fig 3. Comparision of flexibility between native and foreign domains

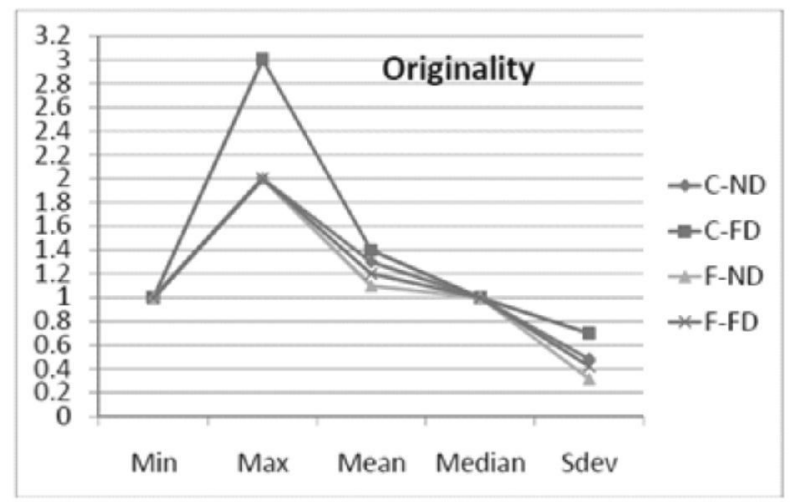

Fig 4. Comparision of originality between native and foreign domains
In the above graphs the $y$-axis represents the normalized scores whereas the $\mathrm{x}$-axis represents the skill categories (Minimum, Maximum, Mean, Median, and Standard Deviation).

\section{Conclusions}

1. Creative levels in control group are higher than in fixation group in both native and foreign domain groups.

2. The hypothesis $\mathrm{H} 1$ and $\mathrm{H} 2$ considered in the present work are proved.

3. The results also indicate the need for modifying the teaching paradigm for engineering education to increase the emphasis on innovation and creativity in the curriculum.

4. The present work is being planned to extend to other design skills as well. Plans are also underway to conduct the task in few more Institutes / Universities to observe the variation on a large sample as well as to validate the results.

\section{Acknowledgments}

The authors would like to acknowledge the support of the Department of Science and Technology, New Delhi under Grant No: SR/CSI/130/2011(G) to carry out the present research. The authors also acknowledge the support of the Management, Director and Principal of SR Engineering College (A), Warangal in carrying out this research work.

\section{References}

[1]H. Herzberger, "Lessons for Student in Architecture", Rotterdam, Uitgeverij, 1991.

[2] Linsey, J.S., Tseng, I., Fu, K., Cagan, J., Wood, K.L. and Schunn, C., A Study of Design Fixation, Its Mitigation and Perception in Engineering Design Faculty. Journal of Mechanical Design, 2010, 132(4), pp041003.

[3] Jansson, D. and Smith, S., Design fixation. Design Studies, 1991, 12(1), pp3-11.

[4] Purcell, A. and Gero, J., Design and other types of fixation. Design Studies, 1996, 17(4), ?pp363383.

[5] Kiriyama, T. and Yamamoto, T., Strategic knowledge acquisition: a case study of learning ?through prototyping. Knowledge-based Systems, 1998, 11(7-8), pp399-404. 
[6] Viswanathan, V.K. and Linsey, J.S., Design Fixation in Physical Modeling: An Investigation on the Role of Sunk Cost. International Conference on Design Theory and ?Methodology Washington, DC, 2011.

[7] Viswanathan, V.K. and Linsey, J.S., Understanding Physical Models in Design Cognition: A ?Triangulation of Qualitative and Laboratory Studies. Frontiers in Education Rapid City, SD, ?2011.
[8] D.W Dahl, and P. Moreau, "The Influence and Value of Analogical Thinking During New Product Ideation," J. Mark. Res., 2002, 39, 1, pp. 47-60.

[9] R.L Marsh, J.D Landau, and J.L Hicks, "How Examples May and May Not Constrain Creativity," Memory Cognition., 1996, 24, 5, pp. 669-680. 